\title{
Ultrasound-Guided Transversus Abdominis Plane block versus Ultrasound-Guided Caudal Block for Pain Relief in Children Undergoing Lower Abdominal Surgeries
}

\author{
Osama Helal Ahmed ${ }^{\mathbf{1}}$, Waheed Mohamed Ali ${ }^{\mathbf{1}}$, Ibrahim Elabd Hassan*2 \\ Departments of Anesthesiology \& Intensive Care Faculty of Medicine, Al Azhar (Assuit) ${ }^{1}$ and Aswan ${ }^{2}$ \\ Universities \\ *Corresponding author: Ibrahim Elabd Hassan, Mobile: (+20)01001313392, E-mail: haemty2010@ gmail.com
}

\begin{abstract}
Background: Transversus abdominis plane (TAP) block has been described as an effective technique to reduce postoperative pain intensity. Also, Caudal analgesia with local analgesics is effective but is often short-lived and associated with an undesired motor blockade and other complications.

Objective: This prospective, randomized, controlled clinical study aimed to compare the effectiveness of analgesia by using ultrasound guidance for TAP block and caudal analgesia in children undergoing lower abdominal surgery.

Patients and Methods: This prospective, randomized, controlled study included 60 children aged between 2 to 6 years, scheduled for elective lower abdominal surgery. Group A $(n=20)$ received an ultrasound TAB block. Group B $(n=20)$ received ultrasound-guided caudal block Group C $(n=20)$ who was the controlled group received conventional analgesia. The intraoperative assessment included HR, systolic, diastolic and mean BP, need for rescue analgesia postoperative pain scores and parent satisfaction

Results: No significant difference between all groups regarding demographic data, type and duration of surgery and intraoperative hemodynamic values. The control group had the highest number of patients and doses needed for rescue analgesia while $\mathrm{TAB}$ showed the lowest. The $\mathrm{TAB}$ group patient showed the highest degree of parent satisfaction than the other two groups.

Conclusions: The study showed that $\mathrm{TAB}$ and Caudal block effective in postoperative pain-relieving in lower abdominal surgery in children however patients who received $\mathrm{TAB}$ block required less postoperative rescue analgesia with a better impact on pain scores than caudal block TAB show better parent satisfaction and earlier home discharge.
\end{abstract}

Keywords: Transversus abdominals plane block, Caudal block, Lower abdominal surgery.

\section{INTRODUCTION}

The well-known side effects of painful experience on the young nervous system are so significant that long-term effects can occur, including a lowered pain tolerance for months after a painproducing event ${ }^{(\mathbf{1}, \mathbf{2})}$.

The abdominal wall is a significant source of pain after abdominal surgery. Even a relatively small operation such as inguinal herniorrhaphy may be followed by a risk of a chronic pain state in about $12 \%$ of patients, with clinically significant effects on daily activities if postoperative pain is not taken care of. Regional analgesic techniques have gained widespread popularity as an important component of postoperative analgesia regimens ${ }^{(3)}$. During the last decade, the use of ultrasound-guided regional anesthesia has increased, and developments in ultrasound technology have enabled direct visualization of peripheral nerves ${ }^{(4)}$. In pediatric patients, ultrasound-guided blocks have been associated with a higher success rate and a lower volume of local anesthetic needed, compared with the conventional landmark-based techniques ${ }^{(5)}$.

The abdominal wall has three muscle layers: external and internal obliques, and transversus abdominis. They are innervated by mixed somatic nerves that course between the transversus abdominis and the internal oblique muscles ${ }^{\left({ }^{(}\right)}$.
Caudal analgesia with local analgesics is effective but is often short-lived and associated with an undesired motor blockade and other complications (7). Recently, the transversus abdominis plane (TAP) block has been described as an effective technique to reduce postoperative pain intensity and morphine consumption after lower abdominal surgery ${ }^{(6)}$.

\section{AIM OF THE WORK}

This prospective, randomized, controlled clinical study aimed to compare the effectiveness of analgesia by using ultrasound guidance for TAP block and caudal analgesia in children undergoing lower abdominal surgery.

\section{PATIENTS AND METHODS}

After approval of medical ethics committee in the Department of Anesthesia and Intensive Care, AlAzhar faculty of medicine (Assuit) and obtaining an informed written consent from the child parents / guardians this prospective, randomized, controlled clinical study included 60 children from both genders, aged between 2 to 6 years, with an ASA physical status of I and II, who were scheduled for elective lower abdominal surgery. 


\section{Methods:}

The number of cases included in this study was simple randomly allocated into three groups (20 in each):

Group A ( $\mathrm{n}=20)$ : TAP block group: received ultrasound-guided transversus abdominis plane (TAP) block.

Group B ( $=20)$ : Caudal block group: received ultrasound-guided caudal block.

Group C ( $n=20)$ :Control group: received standard anesthesia protocol.

\section{Methods of randomization:}

- Randomization of patients was done using a computerized program.

- Sealed envelopes were numbered according to the randomization tables.

- Packing, sealing, and numbering of envelopes was performed by neutral medical personnel (under the supervision of doctors from the Department of Anesthesiology and intensive care).

Sample size justification: The sample size is calculated using EpiInfo ${ }^{\circledR}$ version 6.0, setting the type-1 error $(\alpha)$ at 0.05 and the power $(1-\beta)$ at 0.80 .

Equipments used in the study: Ultrasound machine (SonoSite ${ }^{\mathrm{TM}}$ M-Turbo USA) and scanning probe (linear multi-frequency 13-6 MHz) were used. While the drug used in the present study was Bupivacaine $\mathrm{HCL}$ injection $(5 \mathrm{mg} / \mathrm{ml})$.

\section{Anesthetic Procedure:}

\section{Preoperative Assessment:}

- Preoperative visit and assurance.

- All patients were assessed clinically and investigated for the exclusion of any of the above-mentioned contraindications.

- The needed laboratory work was, Complete blood count (CBC); prothrombin time (PT) and concentration (PC), partial thromboplastin time (PTT), bleeding time (BT), clotting time (CT), renal and liver function tests

Patient monitoring:

- Pulse oximetry.

- ECG.

- Non-invasive blood pressure (NIBP) monitoring.

- Capnography.

- Temperature.

\section{Induction of anesthesia:}

- Pre-oxygenation was applied for 4 min using a facemask and oxygen 100\%. General anesthesia was induced using fentanyl $(2 \mu \mathrm{g} / \mathrm{kg})$, propofol $(2-2.5) \mathrm{mg} / \mathrm{kg}$ over 20 30 seconds as tolerated and atracurium $(0.5$ $\mathrm{mg} / \mathrm{kg}$ ) to facilitate endotracheal intubation.

- The patients were intubated by appropriate size (age/4+4 formula) of an endotracheal tube, fixed to mouth opening at an adequate length
- (age $/ 2+12$ formula) after ensuring bilateral chest equality of air entry and steadiness of capnography waves.

\section{Maintenance of anesthesia:}

- Anesthesia was maintained by:

- Isoflurane (1.2\%) in $100 \%$ oxygen.

- Atracurium maintenance dose according to time

- Intraoperative fluid therapy using lactated ringer's solution according to child weight (42-1 formula) with care for replacement of losses (blood loss and third space).

Intraoperative measurements:

1. Hemodynamic parameters (mean arterial blood pressure (MAP) and heart rate (HR) were recorded preoperatively, at skin incision and every 5 minutes till 15 minutes, then every 15 minutes till the end of surgery.

2. The number of patients in each group who needed increase in analgesic requirements all through the procedure by measuring the frequency of extra analgesic need of fentanyl $0.5 \mu \mathrm{g} / \mathrm{kg}$ and the number of doses for each patient.

3. Incidence of complications in the form of hemodynamic instability, injury to the underlying structures (injury to the liver or a viscous), and hematoma formation as recorded under ultrasound guidance.

\section{Postoperative measurements:}

1. Pain assessment using 2 pain scores: a. CHEOPS pain score. b. OPS pain score.

2. The number of patients in each group who needed rescue doses of IV paracetamol (and the number of doses for each patient).

3. The general satisfaction of the patients and/or their parents/guardians were also considered and recorded.

\section{Statistical Analysis}

Statistical analyses were performed using IBM SPSS Statistics version 20 (SPSS Inc., Chicago, IL, USA). Categorical data were presented as frequencies and percentages, while Chi-square tests were used for comparisons between groups. Continuous data were reported as mean $\pm \mathrm{SD}$ or median (Min-Max) and tested for normality using the Shapiro-Wilkes test. Where continuous data were normally distributed, the one-way ANOVA was used for comparisons between groups; where data were non-normally distributed, the Kruskal-Wallis test was used. P-value $<0.05$ was considered statistically significant.

\section{RESULTS}

Demographic data, type, and duration of surgery: There was no statistically significant difference (P-value $>0.05$ ) among the three groups according to demographic data (Gender, Age, ASA, Weight), type of surgery or duration of surgery in minutes. 
Table (1): Type of surgery of the studied groups:

\begin{tabular}{|l|c|c|c|c|}
\hline & $\begin{array}{c}\text { TAB } \\
(\mathbf{n}=\mathbf{2 0})\end{array}$ & $\begin{array}{c}\text { Caudal } \\
(\mathbf{n}=\mathbf{2 0})\end{array}$ & $\begin{array}{c}\text { Control } \\
(\mathbf{n = 2 0})\end{array}$ & \multirow{2}{*}{-value $^{\wedge}$} \\
\cline { 1 - 4 } Hernia & $10(50 \%)$ & $8(40 \%)$ & $7(35 \%)$ & \multirow{2}{*}{0.777} \\
\cline { 1 - 4 } Hydrocele & $2(10 \%)$ & $6(30 \%)$ & $5(25 \%)$ & \\
\cline { 1 - 3 } Undescended testicles & $6(30 \%)$ & $4(20 \%)$ & $5(25 \%)$ & \\
\cline { 1 - 4 } Colostomy closure & $2(10 \%)$ & $2(10 \%)$ & $3(15 \%)$ & \\
\hline
\end{tabular}

Data presented as number \& percentage $n(\%)$.

${ }^{\wedge}$ Chi-square test was used.

Intra-operative Mean Arterial Blood Pressure (MAP) and Heart Rate (HR):

Through all periods of intra-operative measurement, there was no statistically significant difference (P-value $>0.05)$ in mean arterial blood pressure (MAP) or heart rate (HR) among the three groups (Figure 1\&2).

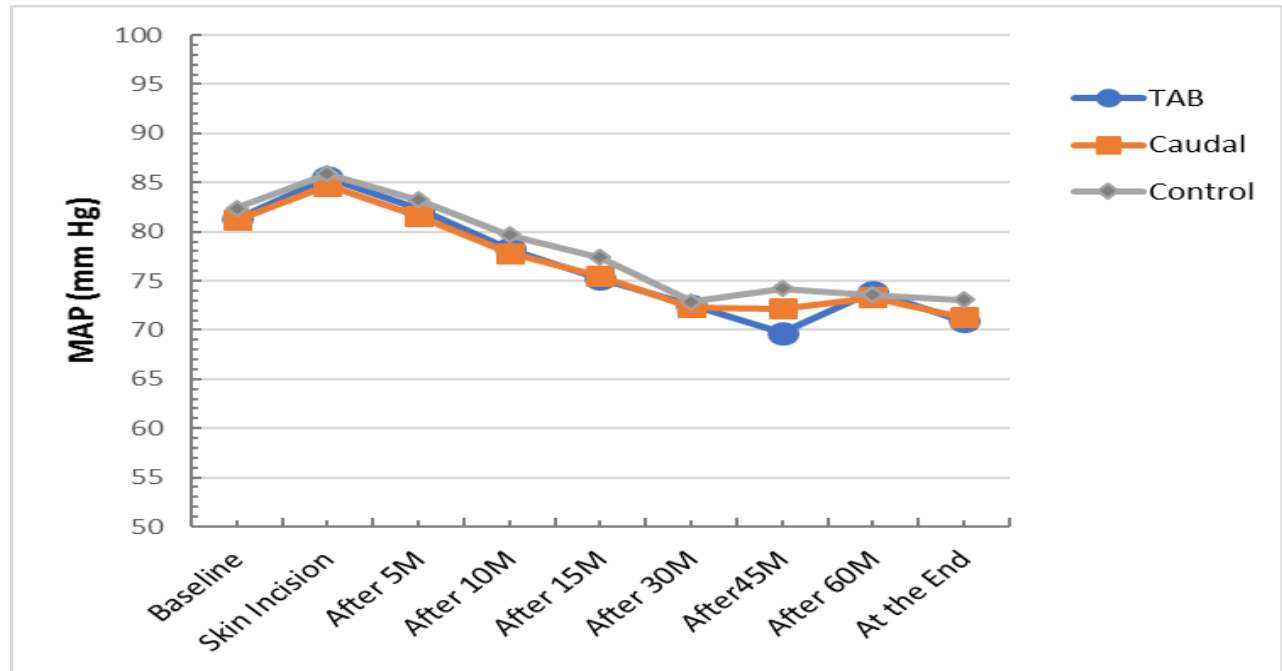

Fig. (1): Intra-operative MAP of the studied groups.

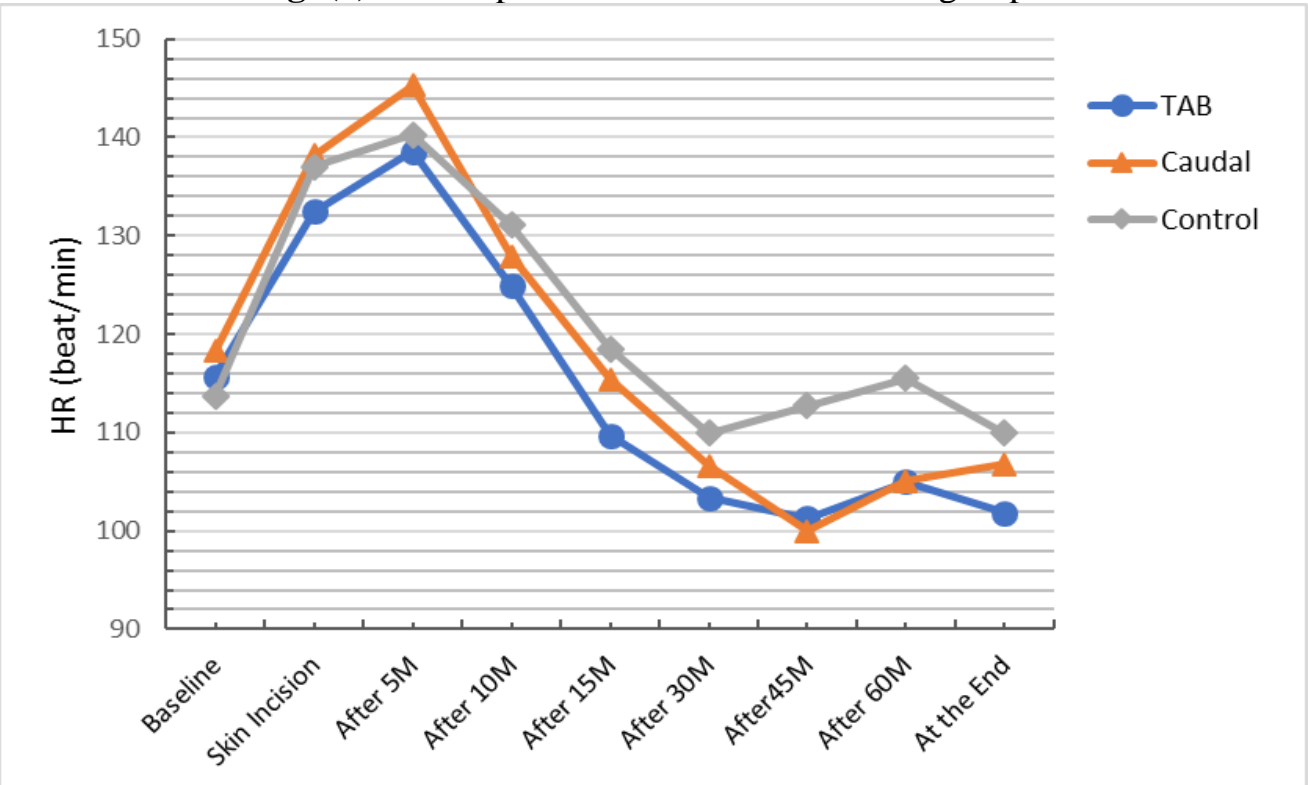

Fig. (2): Intra-operative HR of the studied groups.

Post-operative pain scores:

Children's Hospital Eastern Ontario Pain Scale (CHEOPS):

The intergroup comparison showed a statistically significant difference $(\mathrm{P}$-value $<0.05)$ between groups according to CHEOPS (Median and range) (Table 2).

At arrival to PACU, 2, 6 and 12 hours post-operative, the control group showed a statistically significant difference from the other two groups.

At times 4 and 8 hours post-operative, the TAB group showed statistically significant difference than caudal and control groups. 
Table (2): Difference of post-operative CHEOPS between the studied groups:

\begin{tabular}{|l|l|l|l|l|}
\hline & $\begin{array}{l}\text { TAB } \\
(\mathbf{n = 2 0})\end{array}$ & $\begin{array}{l}\text { Caudal } \\
(\mathbf{n = 2 0})\end{array}$ & $\begin{array}{l}\text { Control } \\
(\mathbf{n = 2 0})\end{array}$ & p-value $^{\wedge}$ \\
\hline At arrival to PACU & $4(4-5)^{\mathrm{a}}$ & $4.5(4-5)^{\mathrm{a}}$ & $7(4-8)^{\mathrm{b}}$ & $<0.001^{*}$ \\
\hline $\mathbf{2}$ hrs. post-operative & $5(4-5)^{\mathrm{a}}$ & $5(4-6)^{\mathrm{a}}$ & $6(4-8)^{\mathrm{b}}$ & $0.001^{*}$ \\
\hline $\mathbf{4}$ hrs. post-operative & $5(4-6)^{\mathrm{a}}$ & $6(3-8)^{\mathrm{b}}$ & $5(4-8)^{\mathrm{b}}$ & $0.008^{*}$ \\
\hline $\mathbf{6 ~ h r s . ~ p o s t - o p e r a t i v e ~}^{\mathrm{b}}$ & $5(4-5)^{\mathrm{a}}$ & $4.5(4-7)^{\mathrm{a}}$ & $5(4-7)^{\mathrm{b}}$ & $0.024^{*}$ \\
\hline $\mathbf{8}$ hrs. post-operative & $5(4-5)^{\mathrm{a}}$ & $5(4-7)^{\mathrm{b}}$ & $5(4-8)^{\mathrm{b}}$ & $0.021^{*}$ \\
\hline $\mathbf{1 2}$ hrs. post-operative & $5(2-6)^{\mathrm{a}}$ & $5(4-5)^{\mathrm{a}}$ & $5(4-7)^{\mathrm{b}}$ & $0.003^{*}$ \\
\hline
\end{tabular}

Data presented as Median (min-Max)

${ }^{\wedge}$ Kruskal-Wallis test was used. * significant p-value

\section{Objective Pain Score (OPS):}

The intergroup comparison showed a statistically significant difference $(\mathrm{P}$-value $<0.05)$ between all groups according to OPS (Median and range) (Table 3).

At arrival to PACU, 2, 6 and 12 hours post-operative, the control group showed a statistically significant difference from the other two groups.

At times 4 and 8 hours post-operative, the TAB group showed statistically significant difference than the caudal and control groups.

Table (3): Difference between post-operative OPS of the studied groups:

\begin{tabular}{|l|l|l|l|l|}
\hline & $\begin{array}{l}\text { TAB } \\
(\mathbf{n = 2 0})\end{array}$ & $\begin{array}{l}\text { Caudal } \\
(\mathbf{n = 2 0})\end{array}$ & $\begin{array}{l}\text { Control } \\
(\mathbf{n = 2 0})\end{array}$ & p-value $^{\wedge}$ \\
\hline At arrival to PACU & $3(2-5)^{\mathrm{a}}$ & $3(2-5)^{\mathrm{a}}$ & $5(3-8)^{\mathrm{b}}$ & $<0.001^{*}$ \\
\hline $\mathbf{2}$ hrs. post-operative & $3(2-4)^{\mathrm{a}}$ & $3(2-5)^{\mathrm{a}}$ & $4(3-8)^{\mathrm{b}}$ & $0.003^{*}$ \\
\hline $\mathbf{4}$ hrs. post-operative & $3(2-6)^{\mathrm{a}}$ & $5(2-7)^{\mathrm{b}}$ & $4.5(3-6)^{\mathrm{b}}$ & $0.029^{*}$ \\
\hline $\mathbf{6 ~ h r s . ~ p o s t - o p e r a t i v e ~}^{\mathrm{a}}$ hrs. post-operative & $3(2-5)^{\mathrm{a}}$ & $4(3-6)^{\mathrm{a}}$ & $4(3-7)^{\mathrm{b}}$ & $0.005^{*}$ \\
\hline $\mathbf{1 2}$ hrs. post-operative & $3(2-4)^{\mathrm{a}}$ & $3(2-6)^{\mathrm{b}}$ & $4(3-6)^{\mathrm{b}}$ & $0.005^{*}$ \\
\hline
\end{tabular}

Data presented as Median (min-Max)

${ }^{\wedge}$ Kruskal-Wallis test was used.

* significant p-value.

Need for rescue analgesia, time to first dose and number of doses:

All patients in the control group needed rescue analgesia compared to only 4 (20\%) and $10(50 \%)$ of patients in TAB and caudal groups and this was statistically significant $(\mathrm{P}<0.05)$.

Table (4): Number of patients needed rescue analgesia:

\begin{tabular}{|l|l|l|l|l|}
\hline & $\begin{array}{l}\text { TAB } \\
(\mathbf{n = 2 0})\end{array}$ & $\begin{array}{l}\text { Caudal } \\
(\mathbf{n = 2 0})\end{array}$ & $\begin{array}{l}\text { Control } \\
(\mathbf{n = 2 0})\end{array}$ & p-value $^{\wedge}$ \\
\hline $\mathbf{N}(\%)$ & $4(20 \%)^{\mathrm{a}}$ & $10(50 \%)^{\mathrm{a}}$ & $20(100 \%)^{\mathrm{b}}$ & $<0.001^{*}$ \\
\hline
\end{tabular}

Data presented as number \& percentage $n(\%)$.
$\wedge$ Chi-square test was used.
* Significant p-value.

Regarding time to first rescue analgesia: the control group showed a statistically significant difference (P-value $<0.05)$ than TAB and Caudal groups. The time interval to give the first rescue dose of analgesia was shorter in the control group and the longest in the TAB group.

Table (5): Time to the first dose of rescue analgesia:

\begin{tabular}{|l|l|l|l|l|l|}
\hline \multicolumn{2}{|c|}{} & $\begin{array}{l}\text { TAB } \\
(\mathbf{n = 2 0})\end{array}$ & $\begin{array}{l}\text { Caudal } \\
(\mathbf{n = 2 0})\end{array}$ & $\begin{array}{l}\text { Control } \\
(\mathbf{n = 2 0})\end{array}$ & p-value \\
\hline $\begin{array}{l}\text { Time of 1 } 1^{\text {st }} \\
\text { analgesia }\end{array}$ & Mean \pm SD & $3.0 \pm 2.6^{\mathrm{a}}$ & $2.0 \pm 0.9^{\mathrm{a}}$ & $0.7 \pm 0.9^{\mathrm{b}}$ & \multirow{2}{*}{$<0.001^{*}$} \\
\cline { 2 - 6 } & Median (Mi-Max) & $3(0-6)$ & $3(2-6)$ & $0(0-2)$ & \\
\hline
\end{tabular}

Data presented as mean $\pm S D$ and Median (Min-Max).

$\wedge$ One-way ANOVA was used. * Significant p-value. 
Regarding the number of rescue doses and total dose of analgesia: there is a statistically significant difference between all groups. The control group received a number of rescue doses higher than that for TAB and Caudal groups.

Table (6): Number of doses of rescue analgesia:

\begin{tabular}{|c|c|c|c|c|}
\hline & $\begin{array}{l}\text { TAB } \\
(n=20)\end{array}$ & $\begin{array}{l}\text { Caudal } \\
(\mathrm{n}=20)\end{array}$ & $\begin{array}{l}\text { Control } \\
(\mathbf{n}=20)\end{array}$ & $p$-value ${ }^{\wedge}$ \\
\hline Mean \pm SD & $0.3 \pm 0.6^{\mathrm{a}}$ & $1.4 \pm 0.5^{\mathrm{a}}$ & $2.1 \pm 1.0^{\mathrm{b}}$ & $<0.001^{*}$ \\
\hline 0 Dose & $16(80 \%)$ & 0 & 0 & \multirow{4}{*}{$<0.001 *$} \\
\hline 1 Dose & $2(10 \%)$ & $12(60 \%)$ & $6(30 \%)$ & \\
\hline 2 Doses & $2(10 \%)$ & $8(40 \%)$ & $6(30 \%)$ & \\
\hline 3 Doses & 0 & 0 & $8(40 \%)$ & \\
\hline
\end{tabular}

Data presented as mean $\pm S D$ and number \& percentage $n(\%)$.

$\wedge$ One-way ANOVA and Chi-square tests were used.

* Significant p-value.

\section{Parents and/or patients satisfaction:}

Table 7 showed a statistically significant difference $(\mathrm{P}$-value $<0.05)$ between all groups according to the degree of parents and/or patients' satisfaction. The TAB group patients showed the highest degrees of satisfaction, then the caudal group, while control group patients had expressed most degrees of dissatisfaction. (Figure 8) Table (7): Parents/ patients satisfaction level of studied groups:

\begin{tabular}{|c|c|c|c|c|}
\hline & $\begin{array}{l}\begin{array}{l}\text { TAB } \\
(n=20)\end{array} \\
\end{array}$ & $\begin{array}{l}\text { Caudal } \\
(n=20)\end{array}$ & $\begin{array}{l}\text { Control } \\
(\mathbf{n}=20)\end{array}$ & $p$-value ${ }^{\wedge}$ \\
\hline Completely Satisfied & $12(60 \%)$ & $3(15 \%)$ & 0 & \multirow{4}{*}{$<0.001 *$} \\
\hline Satisfied & $6(30 \%)$ & $8(40 \%)$ & $5(25 \%)$ & \\
\hline Dissatisfied & $2(10 \%)$ & $4(20 \%)$ & $12(60 \%)$ & \\
\hline Completely Dissatisfied & 0 & $5(25 \%)$ & $3(15 \%)$ & \\
\hline
\end{tabular}

Data presented as number \& percentage $n(\%)$.

^ Chi-square test was used. *Significant p-value.

\section{DISCUSSION}

The TAP block is easily performed under ultrasound guidance. The realtime assessment of the LA injection between the internal oblique and transversus abdominis muscles guarantees distribution of the LA solution to the nerves lying under the fascia of the transversus abdominis muscle $^{(8)}$.

Caudal epidural analgesia is a popular and reliable technique in lower abdominal surgeries in children. However, using additives to caudal analgesia in day-care anesthesia is controversial and not recommended ${ }^{(9)}$.

This study demonstrated that TAP block, caudal block provides additional benefits to multimodal analgesia in children undergoing lower abdominal surgery, with TAP block superiority as evidenced by lower pain scores decreased total dose of rescue postoperative analgesia and time to first dose and better patient and parent satisfaction.

As regard time to the first dose and total dose of rescue postoperative analgesia, our study found that the TAB block group was superior to others.

These results agreed with the results of Tobias ${ }^{(10)}$ who demonstrated safe and effective use of ultrasound-guided TAP block in ten pediatric patients in age ranging from 10 months to
8 years, undergoing umbilical and lower abdominal surgeries with $0.3 \mathrm{ml} / \mathrm{kg}$ of $0.25 \%$ bupivacaine and 1:200,000 epinephrine. In that study, the author reported effective postoperative analgesia in 8 out of 10 patients with the first request for postoperative analgesia varying from 7 to 11 hours.

Also the randomized control trial of El Fawy and El Gendy (11) who enrolled Seventy-five children aged 1-7 years with ASA I or II scheduled for day-case unilateral lower abdominal surgeries were randomly allocated to two groups: group $\mathrm{C}$ (caudal block) and group T (TAP block). The two groups were comparable in terms of total intraoperative fentanyl consumed, postoperative tramadol requirement, postoperative pain scores, time to the first administration of rescue analgesia, and postanesthetic care unit time. Children in the TAP group were discharged home significantly earlier than those in the caudal group. The parent satisfaction score was statistically significantly higher in the TAP group when compared with the caudal group. However, the reasons for the better satisfaction might be different as they attributed it to fewer side effects and more rapid achievement of criteria for home discharge in children with TAP and our study attributed it to decreased rescue postoperative analgesia and lower pain scores ${ }^{(11)}$. 
While Cohen et al. ${ }^{(12)}$ compared the effect of a caudal epidural block with local infiltration (splash block) in children undergoing inguinal herniorrhaphy.

Their results showed that the patients in the caudal group did not need a supplemental dose of analgesia, but the last evaluation point for pain assessment in this study was only $2 \mathrm{hr}$ postoperative, unlike our study which was $12 \mathrm{~h}$.

Also, the randomized control trial of Sahin

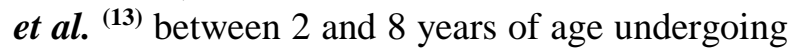
unilateral inguinal hernia repair were randomized to TAP block (group $\mathrm{T}, \mathrm{n}=29$ ) or to wound infiltration (group $\mathrm{C}, \mathrm{n}=28$ ) using $0.25 \%$ levobupivacaine under general anesthesia, The cumulative number of doses of analgesic was significantly lower in group $\mathrm{T}$ than in group $\mathrm{C}$ and The cumulative dose of paracetamol was significantly lower in group $\mathrm{T}$ than in group $\mathrm{C}$.

After comparing the hemodynamic data of the patients in the three groups in our study, we found out that intraoperative mean arterial pressure and heart rate were within the normal limits and did not show any significant increase (>20\%) from the baseline values.

This result was consistent with Fredrickson et al. (14) who performed a prospective study on ultrasound-guided posterior TAP block on eight pediatric patients undergoing inguinal hernia repair and they found no change in heart rate nor mean arterial blood pressure within $20 \%$ of postinduction values.

Against our study, Ashrey and Bosat (15) reported a significant decrease in MAP and HR in the caudal group compared with the penile block group due to the inhibitory effect of bupivacaine on the sympathetic nervous system. In a study conducted on 80 healthy boys aged 1-7 years, of ASA I and II, scheduled for hypospadias repair, circumcision and meatal stenosis under general anesthesia, the patients were randomly divided into two equal groups: group $\mathrm{P}$ (penile block, $0.25 \%$ bupivacaine, $0.5 \mathrm{mg} / \mathrm{kg} ; \mathrm{n}=40$ ) and group $\mathrm{C}$ (caudal block, $0.25 \%$ bupivacaine, $0.5 \mathrm{mg} / \mathrm{kg} ; \mathrm{n}=$ 40). The single-injection penile block was found superior to caudal epidural block for relief of postoperative pain with more satisfaction to the surgeon and the parents, without a significant increase in the rate of adverse events.

Our results showed that there was no incidence of intra or postoperative complications especially with the direct visualization of the site of injection which is neurofascial plane in case of TAB block (group A) and sacral canal in case of Caudal block (group B) and real-time injection of the local anesthetic under ultrasound guidance.

\section{CONCLUSION}

TAP block and caudal block provided adequate relief from postoperative pain in lower abdominal surgeries in children. However, patients who received TAP block required less postoperative rescue analgesia with a better impact on pain scores than a caudal block. TAP block resulted in better parent satisfaction and earlier home discharge when compared with caudal block.

\section{Conflict of Interest Statement:}

The authors declare that there are no conflicts of interest.

\section{Funding and Ethical Consideration:}

No Funding was obtained. The proposal was approved via the Ethical Review Committee of Faculty of Medicine of Al Azhar University (Assuit), before starting the study. Written informed consent was obtained from all recruited patients.

\section{REFERENCES}

1. Andrews K, Fitzgerald M (1999): Cutaneous flexion reflex in human neonates: a quantitative study of threshold and stimulus-response characteristics after single and repeated stimuli. Developmental Medicine and Child Neurology, 41(10):696-703.

2. Taddio A, Katz J, Ilersich AL, Koren G (1997): Effect of neonatal circumcision on pain response during subsequent routine vaccination. The Lancet, 349(9052):599-603.

3. Kehlet H, Wilmore DW (2008): Evidence-based surgical care and the evolution of fast-track surgery. Annals of Surgery, 248(2):189-198.

4. Willschke H, Kettner S (2012): Pediatric regional anesthesia: abdominal wall blocks. Pediatric Anesthesia, 22(1):88-92.

5. O'donnell BD (2006): The transversus abdominis plane (TAP) block in open retropubic prostatectomy. Regional Anesthesia and Pain Medicine, 31(1):91-92.

6. Abdellatif AA (2012): Ultrasound-guided ilioinguinal/iliohypogastric nerve blocks versus caudal block for postoperative analgesia in children undergoing unilateral groin surgery. Saudi Journal of Anaesthesia, 6(4):367-9.

7. Silvani P, Camporesi A, Agostino MR, Salvo I (2006): Caudal anesthesia in pediatrics: an update. Minerva Anestesiol., 72(6):453-9.

8. El-Dawlatly A, Turkistani A, Kettner S, Machata A-M, Delvi M, Thallaj A, Kapral S, Marhofer P (2009): Ultrasound-guided transversus abdominis plane block: description of a new technique and comparison with conventional systemic analgesia during laparoscopic cholecystectomy. British Journal of Anaesthesia,102(6):763-767. 
9. De Beer D, Thomas M (2003): Caudal additives in children-solutions or problems? British Journal of Anaesthesia, 90(4):487-498.

10. Tobias JD (2001): Brachial plexus anesthesia in children. Pediatric Anesthesia, 11(3):265-275.

11. El Fawy DM, El Gendy HA (2014): Ultrasoundguided transversus abdominis plane block versus caudal block for postoperative pain relief in infants and children undergoing surgical pyeloplasty. AinShams Journal of Anaesthesiology, 7(2):177-82.

12. Cohen LL, Lemanek K, Blount RL, Dahlquist LM, Lim CS, Palermo TM, Mckenna KD, Weiss KE (2007): Evidence-based assessment of pediatric pain. Journal of Pediatric Psychology, 33(9):939955.
13. Sahin L, Sahin M, Gul R, Saricicek V, Isikay N (2013): Ultrasound-guided transversus abdominis plane block in children: a randomized comparison with wound infiltration. European Journal of Anaesthesiology (EJA), 30(7):409-414.

14. Fredrickson MJ, Paine C, Hamill J (2010): Improved analgesia with the ilioinguinal block compared to the transversus abdominis plane block after pediatric inguinal surgery: a prospective randomized trial. Pediatric Anesthesia, 20(11):1022-1027.

15. Ashrey EM, Bosat BE (2014): Single-injection penile block versus caudal block in penile pediatric surgery. Ain-Shams Journal of Anaesthesiology, 7(3):428-33. 